\title{
Physcion 8-O- $\beta$-glucopyranoside prevents hypoxia-induced epithelial-mesenchymal transition in colorectal cancer HCT116 cells by modulating EMMPRIN
}

\author{
Z. DING ${ }^{1,2}$, F. XU $U^{3, *}$, J. TANG ${ }^{2}$, G. $\mathrm{LI}^{2}$, P. JIANG ${ }^{2}$, Z. TANG ${ }^{2}$, H. WU ${ }^{2}$
}

${ }^{1}$ Department of General surgery, 2nd affiliated hospital of Soochow University, Suzhou, Jiangsu, 215000, China; ${ }^{2}$ Department of General surgery, Wuxi TCM hospital affiliated to Nanjing University of Chinese Medicine, Wuxi, Jiangsu, 214071, China; ${ }^{3}$ Medical Examination Center, Maternal and child health hospital affiliated to Nanjing Medical University, Wuxi, Jiangsu, 214002, China

*Correspondence: feixuwuxi@163.com

Received July 23, 2015 / Accepted November 10, 2015

\begin{abstract}
Epithelial-mesenchymal transition (EMT) is considered as the most important mechanism that underlies the initiation of cancer metastasis. Here we report that Physicon 8-O- $\beta$-glucopyranoside (PG), a major active ingredient from a traditional Chinese herbal medicine Rumex japonicus Houtt, is capable of preventing human colorectal cancer cells from hypoxiainduced EMT. The treatment of the cells with PG reversed the EMT-related phenotype that has the morphological changes, down-regulation of E-cadherin, and hypoxia-induced cell migration and invasion. The effect was mediated at least in part by inhibiting the mRNA and protein expressions of EMMPRIN via modulation of PTEN/Akt/HIF-1a pathway. In addition, we found that PG-mediated prevention of EMT involved blockade of the hypoxia-induced up-regulation of Snail, Slug and Twist. In summary, this study showed that PG can prevent EMT induced by hypoxia, the environment that commonly exists in the center of a solid tumor. Given the low toxicity of PG to the healthy tissues, our study suggests that PG can serve as a safe therapeutic agent for suppressing cancer metastasis.
\end{abstract}

Key words: colorectal cancer, physcion 8-O- $\beta$-glucopyranoside, hypoxia, EMT, EMMPRIN

Mounting evidences have suggested that the hypoxic environment of the tumor tissue is responsible for the poor response to treatment in most solid tumors including colorectal cancer [1]. The hypoxic environment in most of the rapidly growing solid tumors is resulted from the development of angiogenic vessels which is usually not enough to overcome the necessary oxygen supply [2]. Tumor hypoxia can drive the tumor toward a more aggressive malignant phenotype through clonal selection and genomic and proteomic changes [3]. Moreover, the tumor related hypoxia has been recognized to play a crucial role in rendering the tumor cells insensitive to drugs and radiations due to the poor vascularization of the hypoxic tissue that hinders the transport of drugs to the tumor cells. In the context of colorectal cancer, hypoxia has been reported to play an important role in carcinogenesis and metastasis [4].

As a normal process of embryonic development, epithelialmesenchymal transition (EMT) involves transformation of the epithelial cells to mesenchymal cells which are highly mobile.
Cancer cells have been found to utilize this mechanism of converting immobile epithelial cells into movable mesenchymal cells for their spread [5]. Thus, as a consequence of EMT, specific morphological changes leading to loss of cell-cell tight contact occur in the epithelial cells. The transformed cells acquire characteristics of mesenchymal cells which facilitates their mobility and hence promotes invasiveness into the surrounding tissue and/or distant organs [6]. The epithelial protein E-cadherin is down regulated and mesenchymal proteins, such as vimentin and $\mathrm{N}$-cadherin are up-regulated. Moreover, the cells that have undergone EMT are found to express matrix metalloproteases (MMPs), the major enzymes that participate in the migration, spreading, tissue invasion and metastasis of the tumor cell. Moreover, accumulating data suggest that hypoxia, through inducible factors (HIFs), promotes EMT by regulating the expression and activity of major transcription factors including TWIST, Snail, Slug, SIP1 and ZEB1 [7, 8]. Given the fact that hypoxia-induced EMT plays a key role in metastasis, it appears that EMT can 
be used as a promising target for developing new and effective anti-cancer therapy.

Rumex japonicus Houtt, a perennial herb plant belonging to the family Polygonaceae widely distributed in China (known as Yang-Ti, in Chinese), has been as antimicroorganic, purgative, anti-inflammatory and anti-tumor agents in folk medicine for many years [9-11]. R. japonicus contains a large number of anthraquinones, oxanthrones, and flavones $[9,10]$. Interestingly, a recent research showed that one of the main active ingredient, physicon 8 -O- $\beta$-glucopyranoside(PG), induced apoptosis and caused cycle arrest in human lung cancer cell line A549 [12]. However, little is known on the effect of PG on the EMT of tumor cells. In this study, we used colorectal cancer cell line HCT116 as model to address the suppressing effect of PG in EMT and the underlying mechanisms. Besides showing suppressing effect of PG on EMT, data from this study has identified EMMPRIN as the target of its action, through inhibiting PTEN/Akt/HIF-1a signaling.

\section{Materials and methods}

Cell line and cultures conditions. HCT116 cells were obtained from the American Type Culture Collection (ATCC, Rockville, MD, USA). Cells were grown in RPMI 1640 medium (HyClone, Waltham, MA, USA) containing 10\% fetal bovine serum (HyClone, Waltham, MA, USA) and $1 \%$ antibiotics (100 mg/L streptomycin, $100 \mathrm{U} / \mathrm{ml}$ penicillin) at $37^{\circ} \mathrm{C}$ in a $5 \%$ $\mathrm{CO}_{2}$ atmosphere. Cells were suspended by Trypsin-EDTA (HyClone, Waltham, MA, USA) and separated $1.5 \times 10^{5} / \mathrm{ml}$ at each plate, every 48 hours.

For treatments, cells were seeded in 6-well plate at a density of $5 \times 10^{4} \mathrm{cells} / \mathrm{cm}^{2}$ and cultured in normoxic conditions for 24 hours to allow them to adhere to the substratum. In experiments designed to evaluate the role of hypoxia, cells were first seeded in normoxic conditions to obtain the desired subconfluence level $(65-70 \%)$ and then were incubated in strictly controlled hypoxic conditions $\left(1 \% \mathrm{O}_{2}\right)$ for indicated period of time.

Viability assay. For cell viability assay, HCT116 cells $(1.2 \times$ $10^{5} \mathrm{cells} / \mathrm{ml}$ ) were cultured in 96-well plates and treated with the PG (purchased from Chroma Biotechnology Co. Ltd, Chengdu, China, dissolved in DMSO) at indicated concentration after 24 hours of plating. Anti-neoplastic effects of the drugs were examined after treatment for indicated time by the nonradioactive cell proliferation assay using a commercial kit (Promega Corporation, Madison, WI). The MTT-based method was conducted following the manufacturer's instructions and metabolic conversion of tetrazolium salt to formazan was measured by reading the absorbance at $570 \mathrm{~nm}$.

Wound scratch assay. Each well of 24-well tissue culture plate was seeded with cells to a final density of 100,000 cells per well and these cells were maintained at $37^{\circ} \mathrm{C}$ and $5 \% \mathrm{CO}_{2}$ for 24 hours to permit cell adhesion and the formation of a confluent monolayer. These confluent monolayers then were scored with asterile pipette tip to leave a scratch of approxi- mately $0.4-0.5 \mathrm{~mm}$ in width. Cell surface was then washed with serum-free culture medium for three times to remove dislodged cells. Wound closure was monitored by collecting digitized images at 0,12 and 24 hours after the scratch was performed. Digitized images were captured with an inverted microscope (MOTIC CHINA GROUP CO., Xiamen, China) and digital camera (Nikon, Tokyo, Japan). The digitized images were then analyzed using Image-J software.

Invasion assay. 24-wellTranswells coated with Matrigel (8- $\mu \mathrm{m}$ pore size; BD Biosciences, San Jose, California) were used for cell invasion assays [13]. Equal numbers $\left(1 \times 10^{5}\right)$ cells were plated onto separate well. Cells were starved overnight in serum-free medium, trypsinized and washed three times in DMEM containing $1 \%$ FBS. A total of $1 \times 10^{5}$ cells were then resuspended in $500 \mu \mathrm{l}$ DMEM containing $1 \%$ FBS and added to the upper chamber, while MEM with $10 \%$ FBS was added to the lower chamber as chemoattractant. For the control, medium containing $1 \%$ FBS was added to the lower chamber. After 24 hours of incubation, the Matrigel and the cells remaining in the upper chamber were removed by cotton swabs. The cells on the lower surface of the membrane were fixed in formaldehyde and stained with hematoxylin staining solution. The cells in at least five random microscopic fields (magnification, $\times 200$ ) were counted and photographed.

Immunoflorescence staining and confocal image. Cells were grown on glass coverslip until $80 \%$ confluent, and then fixed with $4 \%$ formaldehyde solution. Transfected and untransfected cells were then incubated with rabbit monoclonal anti- $\beta$-catenin antibody (Cell Signaling Technology, Inc., Beverly, MA, USA, 1:100) for detection of specific protein, respectively. Next, the cells were incubated with Cy3-labeled goat anti-rabbit antibody (Beyotime Institute of Biotechnology, Shanghai, China, 1:100) at room temperature for 1 hour in the dark, followed by incubation with DAPI (Biosharp Biotech., Hefei, China, 1:1000) for 5 minutes before washed three times with PBS to remove excessive staining solution. The cells were then subjected to laser scanning confocal microscope (Olympus FV1000S-SIM/IX81, Tokyo, Japan).

Quantitative RT-PCR (qRT-PCR). Total RNA was extract from cells using RNA simple Total RNA Kit (TIANGEN Co., Beijing, China) and $3 \mu \mathrm{g}$ of RNA was converted into cDNA using the High Capacity cDNA Archive Kit (Applied Biosystems, Foster City, CA, USA). The primers for EMMPRIN, HIF-1 $\alpha$, Slug, Snail and Twist were synthesized based on published sequence $[14,15]$. For each PCR reaction, a master mix that including SYBR GREEN mastermix (Solarbio Co., Beijing, China), forward primer, reverse primer, and 10 ng template $C D N A$ was prepared. The PCR conditions were $5 \mathrm{~min}$ at $95^{\circ} \mathrm{C}$ followed by 40 cycles of $95^{\circ} \mathrm{C}$ for $30 \mathrm{~s}$, $60^{\circ} \mathrm{C}$ for $30 \mathrm{~s}$, and $72^{\circ} \mathrm{C}$ for $30 \mathrm{~s}$. Data were analyzed using the comparative $\Delta \mathrm{Ct}$ method (ABPrism software, Applied Biosystems, Foster City, CA) using GAPDH as an internal normalization control.

Western blot. Western blot analysis was performed using a standard protocol. The cell lysate $(30-50 \mu \mathrm{g})$ samples were 
mixed with $6 \times$ sample buffer, boiled for 5 minutes, electrophoresed in $10 \%$ sodium dodecyl sulfate polyacrylamide gel and there after transferred to PVDF membranes. The membrane was then blocked in PBS containing 5\% bovine serum albumin (BSA) for 1 hour at room temperature. The membranes were incubated with specific primary antibodies in Tris-buffered saline at $4^{\circ} \mathrm{C}$ overnight. After washing, the membranes were incubated with HRP-conjugated secondary antibodies (Beyotime Institute of Biotechnology, Shanghai, China). ECL detection reagent (7Sea Biotech., Shanghai, China) was used for blot detection according to the manufacturer's instructions. The primary antibodies used were mouse polyclonal antibody to EMMPRIN (Sigma, St. Louis, MO), rabbit polyclonal antibody to antibodies against, $\mathrm{N}$-cadherin, E-cadherin, vimentin, fibronectin, $\alpha$-SMA, Snail, Slug, Twist, and PTEN, phospho-Akt (Thr172), Akt (Cell Signaling Technology, Beverly, MA) and a rabbit polyclonal antibody to $\beta$-actin used as a gel loading control.

Luciferase reporter assay. Luciferase reporter assay was performed as described previously [16]. Briefly, the HCT116 cells were seeded into 96-well plates and cultured to $80 \%$ confluence. Cells were then transfected with plasmid containing HIF-responsive elements (HRE) and renilla luciferase-pGL3 as internal control for transfection efficiency using Lipofectamine 2000 reagent (Invitrogen, CA) following manufacturer's instructions. After transfection, the luciferase activity was measured using a commercial kit (Promega Corp., Madison, MI) according to manufacturer's manual.

Silencing HIF-1 $\alpha$ and EMMPRIN with shRNA. For silencing HIF- $1 \alpha$, shRNA targeted HIF-1 $\alpha$ was obtained from Origene (Rockville, MD). For silencing EMMPRIN, the shRNA oligos for EMMPRIN gene knockdown were designed and synthesized as previously described [17]. Scramble shRNA was used as a negative control. shRNA transfection of cells was performed following standard protocol. Briefly, cells were plated at $5 \times 10^{3}$ cells/well in 6-well culture plate and allowed to reach $70-80 \%$ confluence after $24 \mathrm{~h}$ of incubation. The cells were then starved in serumfree culture for 1 hour. The transfection mixture containing EMMPRIN or HIF-1atargeted shRNA and Lipofectamine 2000 (Invitrogen, Carlsbad, CA, USA) was incubated for 20 minutes at room temperature. The cells were then incubated with the above mixture for 5 hours at $37^{\circ} \mathrm{C}$ in a humidified atmosphere containing $5 \% \mathrm{CO}_{2}$. Subsequently, cells were washed with PBS and maintained in DMEM containing 10\% FBS for 48 hours. Success of transfection was confirmed by determining the protein target levels (EMMPRIN or HIF-1 $1 \alpha$ ) through Western blotting).

Generation of plasmid constructs and establishment of EMMPRIN or HIF-1 $\alpha$-ovexpressing cell lines. To investigate the effects of EMMPRIN or HIF-1a on PG-induced suppression on metastatic potential in HCT116 cells, EMMPRIN or HIF-1 $\alpha$ was overexpressed as previously described $[18,19]$. The resulting plasmid was named pCMV-EMMPRIN (HIF1a). HCT116 cells were transfected with pCMV-EMMPRIN
(HIF-1 $\alpha$ ) vector to induce enforced EMMPRIN expression or pCMV vector to generate stable clones expressing EMMPRIN (HIF-1a) constitutively as control. The resulting cell lines were named HCT116/pCMV-EMMPRIN (HIF-1a) and HCT116/pCMV, respectively. Two days after transfection, G418 solution was added to cells for selection of stable clones (HCT116/pCMV-EMMPRIN (HIF-1 $\alpha$ ) and HCT116/pCMV cells). Stable clones were selected and maintained in medium containing G418. Success of transfection was confirmed by determining the protein expression of EMMPRIN or HIF-1 $\alpha$ through Western blotting).

Statistical analysis. Data are expressed as means \pm SD. Analysis of variance (ANOVA) followed by Dunnett's $t$ test were performed to determine if the difference between groups was significant. Values of $\mathrm{P}<0.05$ were considered statistically significant.

\section{Results}

PG prevented the hypoxia-induced migration and invasion of HCT116 cells. First, we examined the effect of PG on hypoxia-induced cell migration and invasion. As shown in Figure 1A, PG suppressed hypoxia-induced cell migration in a dose-dependent manner. PG at $10 \mu \mathrm{g} / \mathrm{ml}$ was not able to showed inhibitory effect on cell migration at both tested time points. In contrast, PG at 20 and $50 \mu \mathrm{g} / \mathrm{ml}$ was able to inhibit cell migration at 12 and 24 hours. Then, the effect of PG on cell invasion was determined by Transwell assay. As shown in Figure 1B, PG also exhibited inhibitory effect on cell invasion in a dose-dependent manner.

PG affected the early changes in EMT markers in hypoxic environment in HCT116 cells. Next we sought to determine if PG mediated the aforementioned effects through modulation of hypoxia-induced EMT. EMT is marked by nuclear translocation of $\beta$-catenin [20]. Thus, we stained cells with $\beta$-catenin antibody and found that there was a dose-dependent accumulation of $\beta$-catenin in the cell membrane relative to cytoplasm and nucleus in the HCT116 cells treated with PG compared to cells treated with vehicle (Figure $2 \mathrm{~A}$ ), which suggested the inhibition on EMT by PG. In addition, the levels of epithelial marker E-cadherin and mesenchymal markers $\mathrm{N}$-cadherin, vimentin, fibronectin and $\alpha$-SMA were examined to support the role of PG in regulating EMT process. As shown in Figure $2 \mathrm{~B}$ and $2 \mathrm{C}$, western blot and qRT-PCR analyses demonstrated that suppression of E-cadherin expression caused by hypoxia was restored with PG treatment. Meanwhile, hypoxia led to a marked up-regulation of $\mathrm{N}$-cadherin, vimentin, fibronectin and $\alpha$-SMA and the effect was suppressed with PG. Taken together, these results clearly indicated that PG inhibited the hypoxia-induced cellular transition from epithelial to mesenchymal phenotype.

PG blocked the hypoxia-induced up-regulation of Snail, Slug and Twist. Transcriptional repressors Snail, Slug and Twist are known to regulate the expression of mesenchymal and epithelial markers and hence play a crucial role in EMT 
[21]. Therefore, in order to completely understand the mechanism of PG's action, we investigated the effect of PG on these regulatory molecules. As shown in Figure 2D and 2E, exposure to hypoxia caused a significant increase in the protein and mRNA expressions of Snail, Slug and Twist. Upon treatment with PG, the hypoxia-caused up-regulation of these transcription repressors was inhibited at both protein and mRNA levels. The results indicate that PG exerted its inhibitory effect on mesenchymal markers by modulating the expression of these transcriptional repressors.

Inhibition of EMMPRIN is involved in the prevention of hypoxia-induced EMT by PG. Accumulating evidence suggests the involvement of EMMPRIN, as a crucial regulator, in the EMT process [22]. Hence, we attempted to explore whether the preventing effect of PG against hypoxia-induced EMT involves modulation of the EMMPRIN expression. As shown in Figure $3 \mathrm{~A}$ and $3 \mathrm{~B}, \mathrm{PG}$ treatment attenuated the hypoxia-triggered upregulation of EMMPRIN in HCT116 cells. To further verify the role of EMMPRIN in hypoxiamediated EMT, we silenced EMMPRIN with shRNA. As it was expected, knockdown of EMMPRIN mimicked the action of PG and inhibited hypoxia-caused EMT, as demonstrated by the change of EMT markers and the levels of Snail, Slug and Twist (Figure 5C-5F). Furthermore, the inhibitory effect of PG on EMT was significantly ettenuated in the cells overexpressing EMMPRIN (Figure 5C-5F). Taken together, our results suggest that $\mathrm{PG}$ prevented the hypoxia-induced EMT by inhibiting HIF-1 $\alpha$.

PG suppresses EMMPRIN expression via PTEN/Akt/ HIF-1a signaling. HIF-1 $\alpha$ activation can cause a series of changes in gene transcription and protein linked to a variety of tumor cell behaviors including apoptosis, invasion and metastasis [23]. It has also been found that HIF-1 a played a role in EMMPRIN regulation [24]. Therefore, we explored whether HIF-1 a signaling was involved in the PG-mediated suppression of EMMPRIN expression. Then HIF-1a expression was artificially manipulated to demonstrate the role of HIF-1 $\alpha$ in EMMPRIN regulation. Under hypoxic condition, HIF-1a knockdown led to significantly suppression in EMMPRIN level while overexpressing HIF-1a resulted in significant attenuation on EMMPRIN levels suppressed by PG (Figure 4A and 4B). All these above findings confirmed our postulation that HIF-1 $\alpha$ was involved in the modulatory effect of PG on EMMPRIN. We then examined the
A

Hypoxia

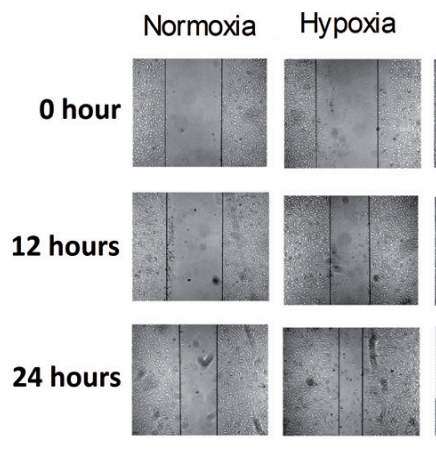

B

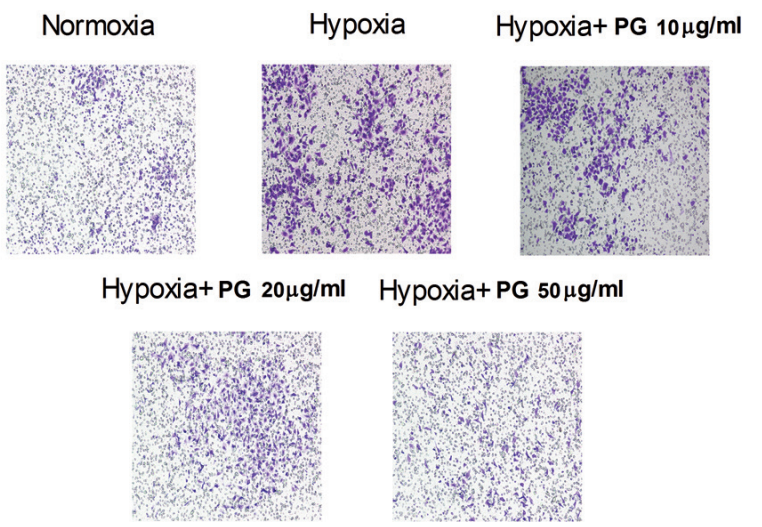

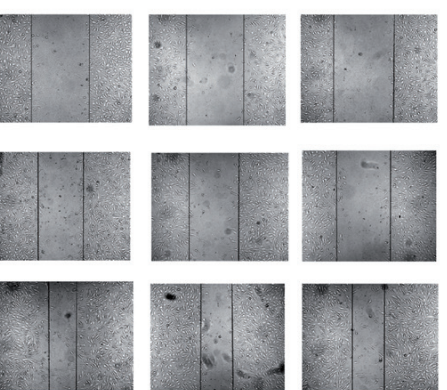
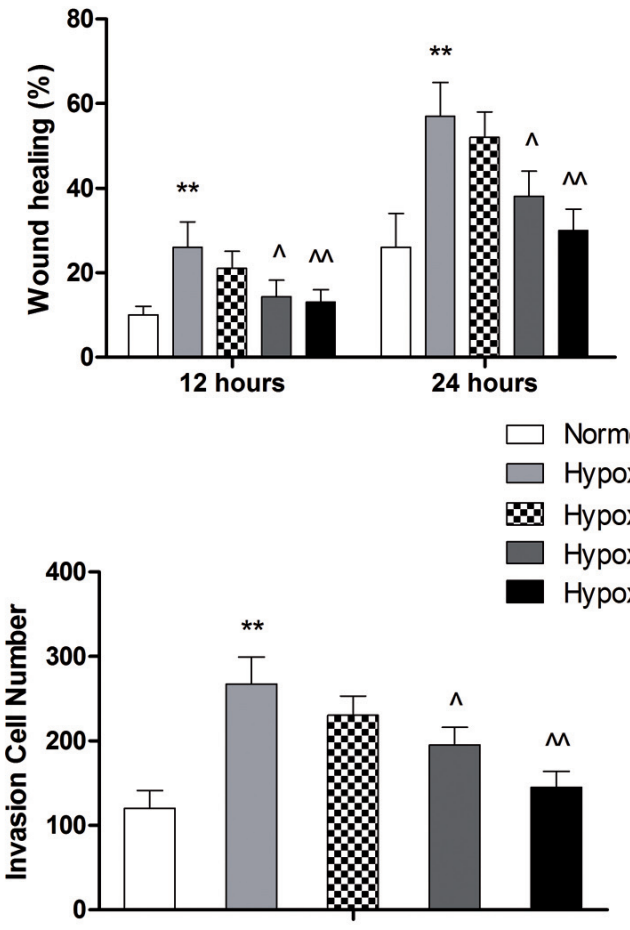

Figure 1. PG suppresses hypoxia-induced migration (A) and invasion (B) in HCT116 cells. HCT116 cells are treated for PG for indicated period of time in hypoxia. Cell migration and invasion are assessed by wound scratch and Transwell assay, respectively. Representative graphs of wound scratch and Transwell assay from three independent experiments are displayed. Data are presented as $\mathbf{m e a n} \pm \mathrm{SD}$. ${ }^{\star} \mathrm{P}<0.05$ vs. control, $\wedge \mathrm{P}<0.05$ vs. hypoxia, $\wedge \wedge \mathbf{P}<\mathbf{0 . 0 1}$ vs. hypoxia. 
mechanism by which PG modulated HIF-1 $\alpha$ in HCT116 cells as HIF-1a expression can be modulated at a different phase including transcription, translation and degradation. The expression of HIF-1 $\alpha$ at mRNA and protein level was assessed by qRT-PCR and western blots respectively. As shown in Figure 4C, dose-dependent decrease in HIF-1a activity was observed. As shown in Figure 5D and 5E, the expression of HIF-1 a mRNA remained unchanged even with

A

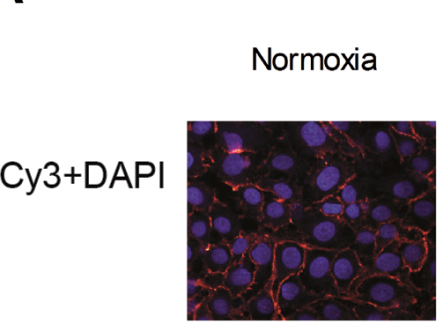

Hypoxia

Hypoxia
${/ \mathrm{ml}} \quad$ PG $20 \mu \mathrm{g} / \mathrm{ml} \quad$ PG $50 \mu \mathrm{g} / \mathrm{ml} }$
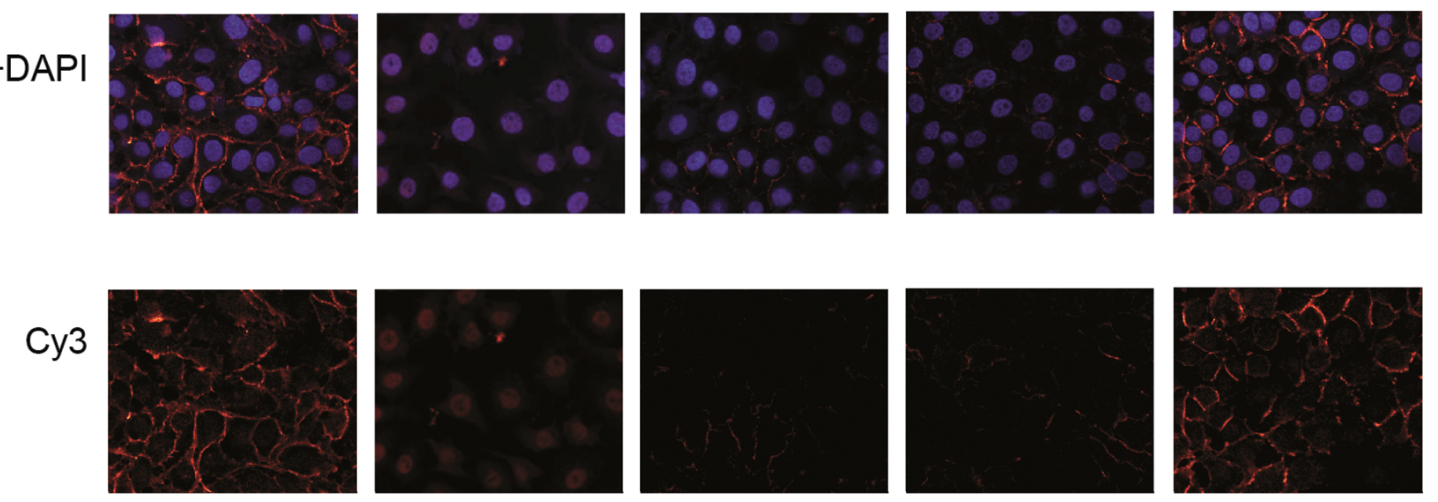

B

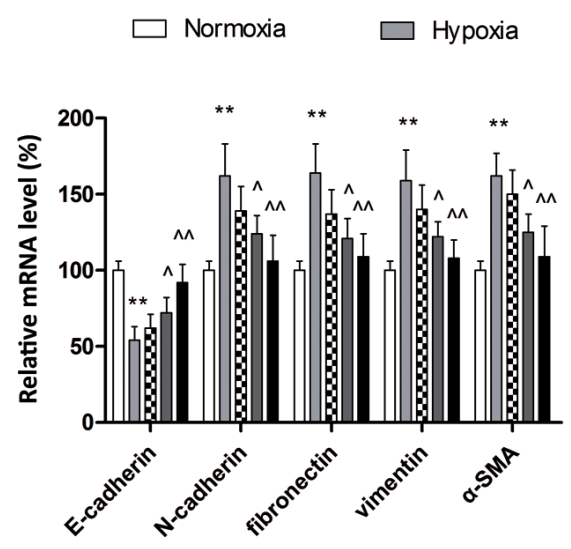

D

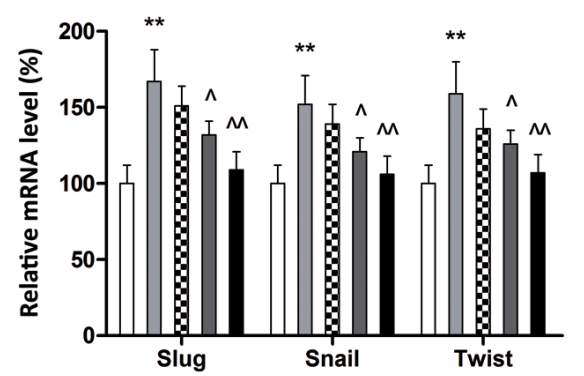

B Hypoxia+PG $10 \mu \mathrm{g} / \mathrm{ml}$ C
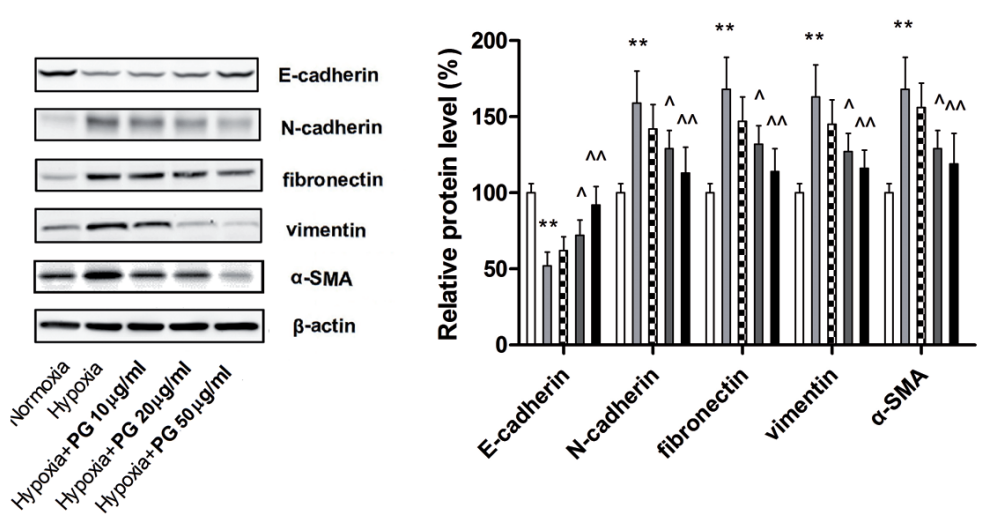

E

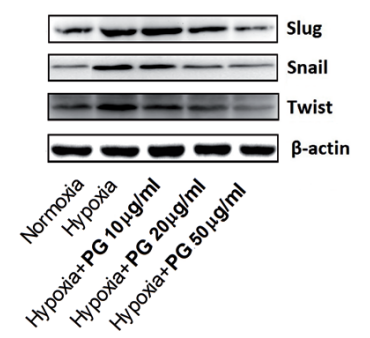

Figure 2. PG prevents hypoxia-induced EMT. HCT116 cells are treated for PGat indicated concentration for 24 hours in hypoxia before assays are performed. (A) The representative graphs of the $\beta$-catenin translocation determined by immno fluorescent staining were displayed. (B) and (C) The effect of PG on expression of epithelial phenotype marker E-cadherin and mesenchymal phenotype marker N-cadherin, vimentin, fibronectin and $\alpha$-SMA were examined by qRT-PCR and western blot. The representative graphs of immunoblots from three independent experiments are displayed. (D) and (E) PG suppressed the expression of Snail, Slug and Twist. The representative graphs of immunoblots from three independent experiments are displayed. Data are presented as mean $\pm S D$. ${ }^{\star} \mathrm{P}<0.05$ vs. control, $\wedge \mathrm{P}<0.05$ vs. hypoxia, $\wedge \wedge \mathrm{P}<0.01$ vs. hypoxia. 
the highest concentration of PG while the protein level was suppressed in a dose-dependent manner by PG. Next, we examined the involvement of the proteasomal degradation of HIF-1 $1 \alpha$ in HCT116 cells treated by using cycloheximide (CHX, a translational inhibitor). HCT116 cells were challenged with CHX alone or in combination with PG for 0,1 , 2, 3 hours. As shown in Figure 4F, our results revealed that HIF-1 $\alpha$ protein degradation rate was significantly higher in HCT116 cells treated by both PG and CHX than CHX alone, which indicated that $\mathrm{PG}$ also interfered with the stabilization of HIF-1 1 in HCT116 cells. Collectively, our results showed that PG modulated HIF-1 1 expression by suppressing de novo synthesis and promoting degradation.

Next step in our study was to investigate the upstream signaling responsible for the regulatory effect of PG on HIFla expression. The crucial role of PTEN/Akt signaling in modulating HIF-1 $\alpha$ in hypoxia has been evidenced [15]. On the other hand, a recent study also reported the inhibitory
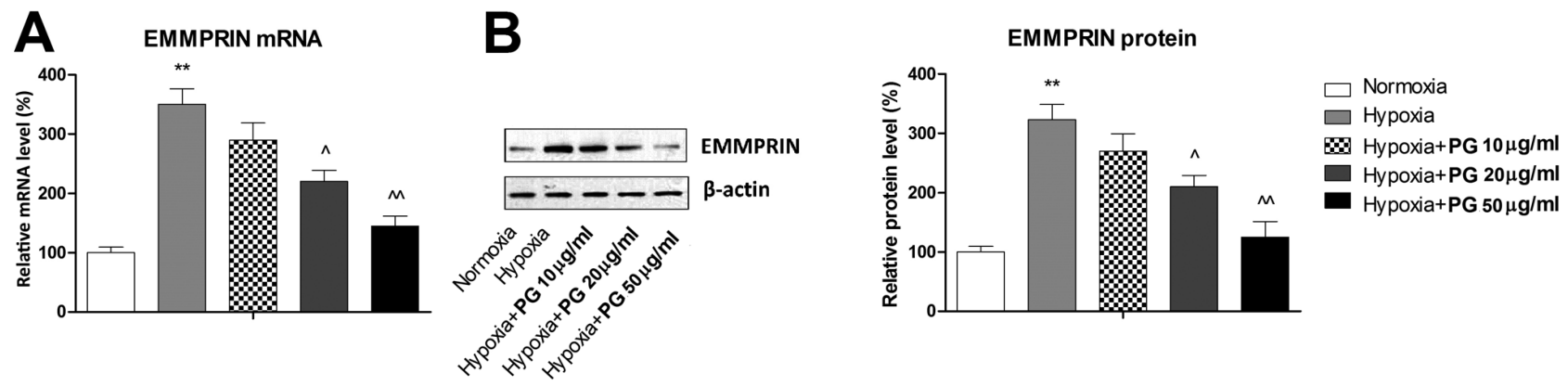

C

D
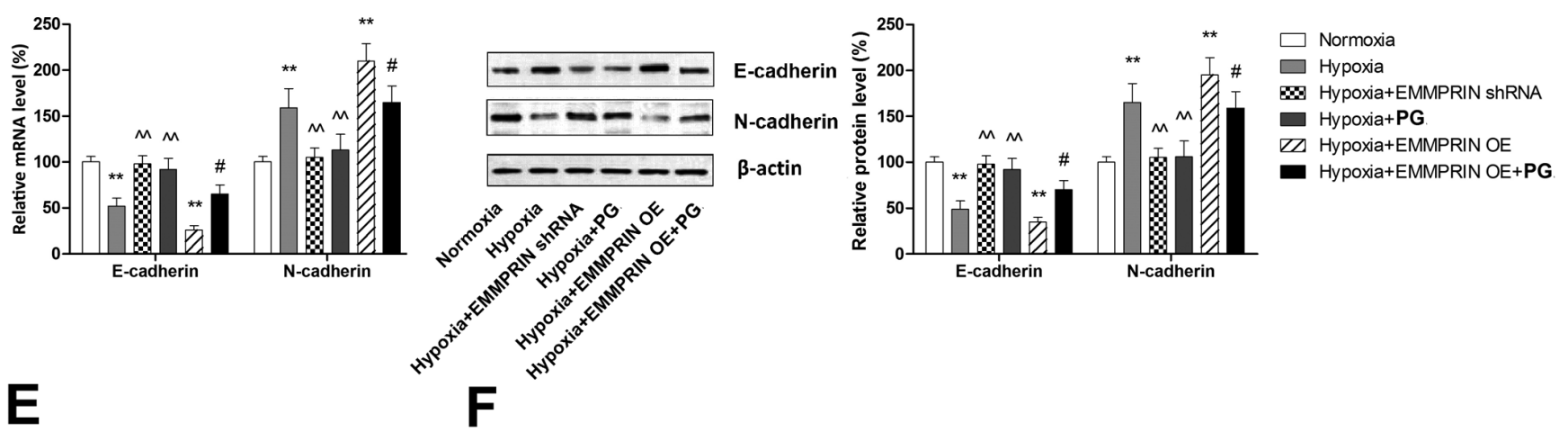

$\mathbf{E}$
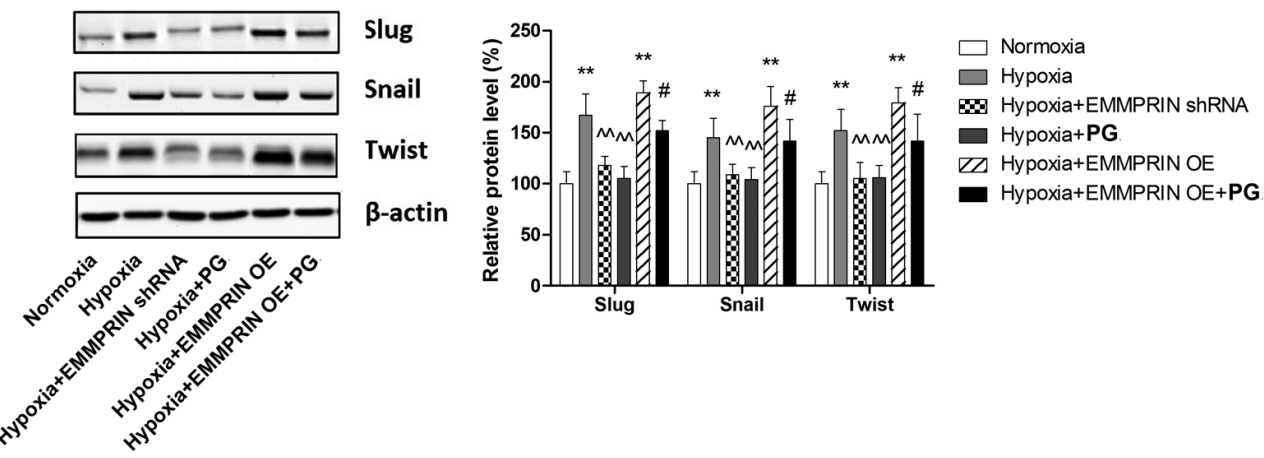

Figure 3. EMMPRIN inhibition is involved in the prevention of hypoxia-induced EMT by PG. HCT116 cells are placed under hypoxic conditions in the presence or absence of PG at indicated concentration (or $50 \mu \mathrm{g} / \mathrm{ml}$ if not marked). (A) and (B) PG suppresses the hypoxia-induced expression of EMMPRIN, as determined by qRT-PCR and western blots. (C) and (D) Silencing EMMPRIN using EMMPRIN -targeting shRNA prevents hypoxiainduced EMT, as demonstrated by restoration of EMT markers level. Overexpression of EMMPRIN partially abrogated the inhibitory effect of PG on hypoxia-induced EMT, as demonstrated by modulation on EMT markers level. (E) and (F) Silencing EMMPRIN using EMMPRIN -targeting shRNA prevents hypoxia-induced EMT, as demonstrated by restoration of Snail, Slug and Twist level. Overexpression of EMMPRIN partially abrogated the inhibitory effect of PG on hypoxia-induced EMT, as demonstrated by modulation on Snail, Slug and Twist level. The representative graphs of immunoblots from three independent experiments are displayed. $\wedge \mathrm{P}<0.05$ vs. hypoxia, $\wedge \wedge \mathrm{P}<0.01$ vs. hypoxia, $\# \mathrm{P}<0.05$ vs. hypoxia $+\mathrm{PG}$. 
of effect of PG on Akt signaling in tumor cells [25]. In this case, we postulated that PG might be able to regulate HIF-1a via PTEN/Akt here. As shown in Figure 5A, PG produced a dramatic elevation of PTEN in a dose-dependent manner as well as inhibition on Akt activation, confirming the effect of PG on PTEN/Akt signaling. Then the involvement of Akt signaling in HIF- $1 \alpha$ and EMMPRIN was examined with Akt inhibitor and Akt activator. In the cells treated with IGF-I (Akt activator) for 4 hours, the level of HIF-1a was significantly elevated, which was reversed by PG at a concentration of 50 $\mu \mathrm{g} / \mathrm{ml}$ (Figure 5F). Meanwhile, treatment of the cells with Akt inhibitor LY294002 was found to significantly reduce the HIF-1 a protein expression (Figure 5F). Corresponding to these observations, the expression of EMMPRIN was significantly reduced with LY294002 and the downregualtion of EMMPRIN by PG was significantly attenuated by IGF-I. Collectively, these findings suggest that PG mediated the inhibtion of PTEN/Akt which in turn caused the repression of HIF- 1 a protein level and subsequent suppression on EMMPRIN levels.

To further support our beforementioned findings, we examined the role of PTEN/Akt signaling in PG-induced inhibition on EMT of HCT116 cells. As shown in Figure 5B, Akt inhibitor LY294002 exhibited significantly inhibitory effect on EMT, as demonstrated by the changes in levels of two important EMT markers and transcriptional repressors, suggesting the regulating role of PTEN/Akt signaling in EMT. In contrast, Akt activator IGF-I significantly abolished the suppressing effect of PG on EMT, confirming that the inhibitory effect of PG on EMT was mediated, at least partly, through PTEN/ Akt signaling.

\section{Discussion}

Cancer cells are characterized by rapid proliferation and require adaptive metabolic responses to allow continued biosynthesis and cell growth in the setting of decreased oxygen $\left(\mathrm{O}_{2}\right)$ and nutrient availability $[26,27]$. The hypoxic microenvironment in the central region of solid tumors is known to induce EMT and promote invasiveness of cancer cells [28]. One of the characteristics of EMT is that instead of epithelial cell marker, E-cadherin, the cells express mesenchymal markers (Vimentin and N-cadherin) [14]. In the
A

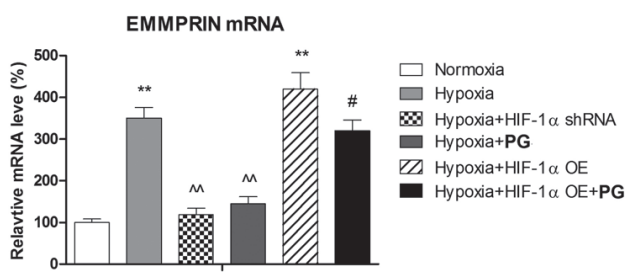

C

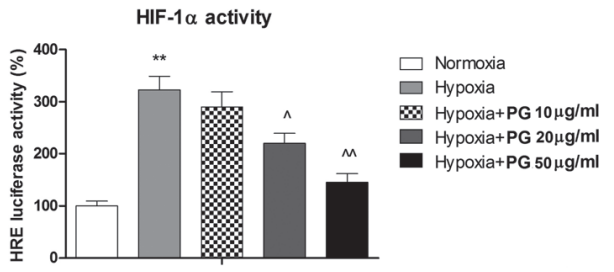

E

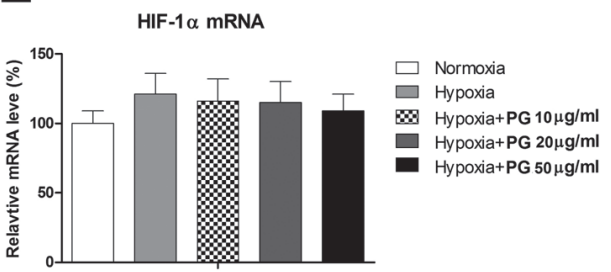

B
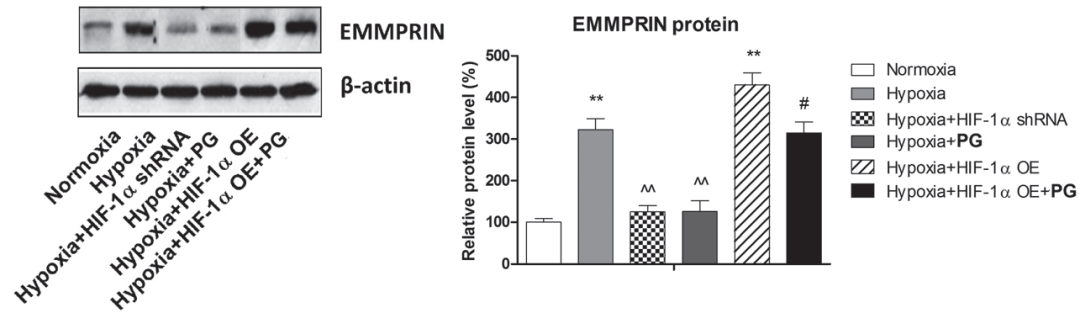

D
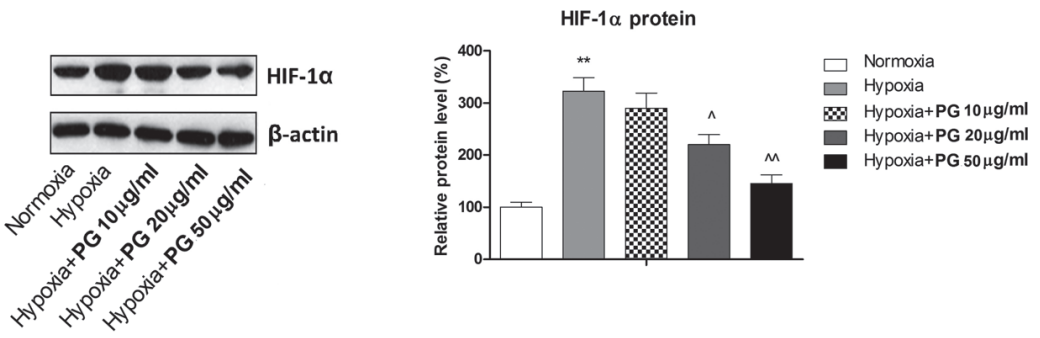

$\mathbf{F}$

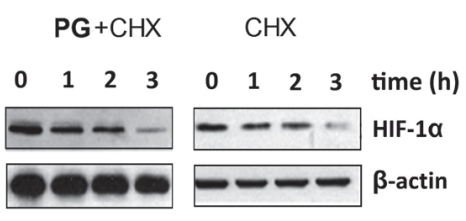

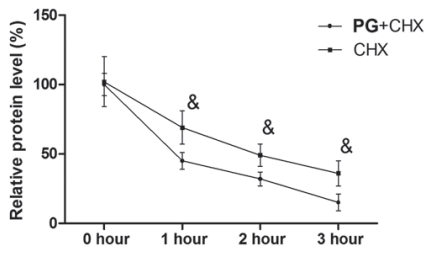

Figure 4. Involvement of HIF-1 1 inhibition in the modulating effect of PG on EMMPRIN. (A) and (B) PG regulated the expression of EMMPRIN by suppressing HIF-1 $\alpha$. (C) PG suppressed HIF-1 $\alpha$ activity in dose-dependent manner. (D). PG suppressed HIF-1 $\alpha$ protein expression in dose-dependent manner. (E) PG did not affect the mRNA expression of HIF-1 $\alpha$. (F). PG promoted the degradation of HIF- $1 \alpha . \wedge P<0.05$ vs. hypoxia, $\wedge \wedge P<0.01$ vs. hypoxia, $\# \mathrm{P}<0.05$ vs. hypoxia $+\mathrm{PG}, \& \mathrm{P}<0.05$ vs. $\mathrm{CHX}$. 
context of colorectal cancer, hypoxia has also been known to affect the stromal cells, a factor associated with poor prognosis [29]. PG, a major active ingredient from a traditional Chinese herbal medicine $R$. japonicus, has also been reported to display anti-cancer effect in vitro [12]. However, the effect of PG on EMT, a phenomenon that plays a vital role in cancer progression and metastasis, has not been studied before. The main finding of the present study is that PG can effectively block the hypoxia-promoted EMT in colorectal cancer cells by inhibiting the PTEN/PI3k/Akt/HIF-1 $\alpha$ signaling pathway, at least in part.

EMMPRIN is a transmembrane glycosylated member of the immunoglobulin superfamily molecules that is expressed on the cell surface of most tumor cells [30-32]. Moreover, a number of studies have showed that elevated EMMPRIN expression is associated with clinically aggressive behavior and poor prognosis in a variety of solid tumors, including colorectal cancer [33-37]. EMMPRIN has been shown to promote tumor invasion and metastasis via stimulating matrix metalloproteinase synthesis in neighboring fibroblasts $[38,39]$, to enhance angiogenesis via vascular endothelial growth factor [40], to induce chemoresistant tumor cells via the production of hyaluronan [41], and to confer resistance of cancer cells to anoikis through inhibition of Bim [42]. EMMPRIN has also been shown to interact with cyclophilin A (CypA) and to facilitate the malignant cell proliferation via the activation of ERK1/2 and p38 mitogen-activated protein kinases [43].In the context of colorectal cancer, clinical data showed that EMMPRIN expression is associated with diseasefree survival of patients with colorectal cancer [44] and serves as an independent biomarker associated with poor prognosis in colorectal cancer [45]. Li et al have also reported that downregulating EMMPRIN expression by RNA interference inhibits HT29 cell proliferation, invasion and tumorigenicity

A

B
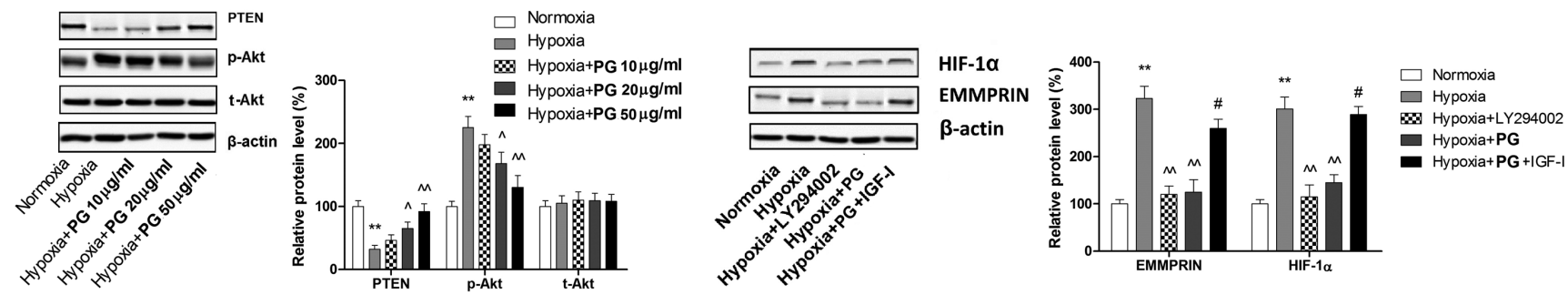

C

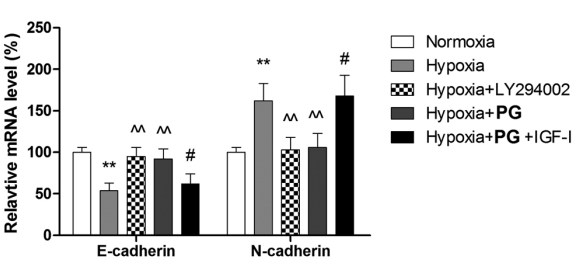

D
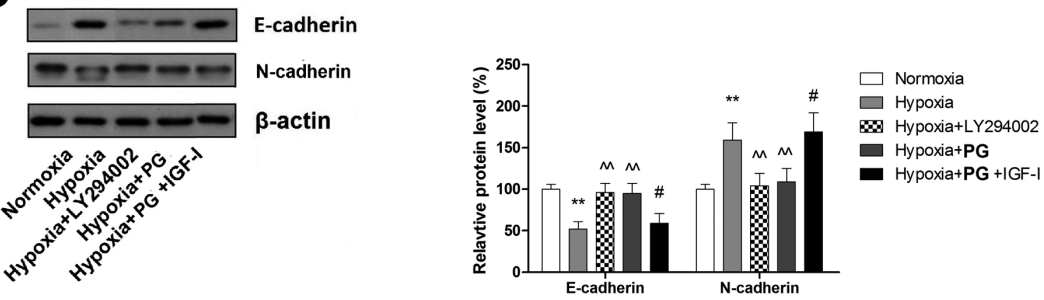

$\mathbf{E}$
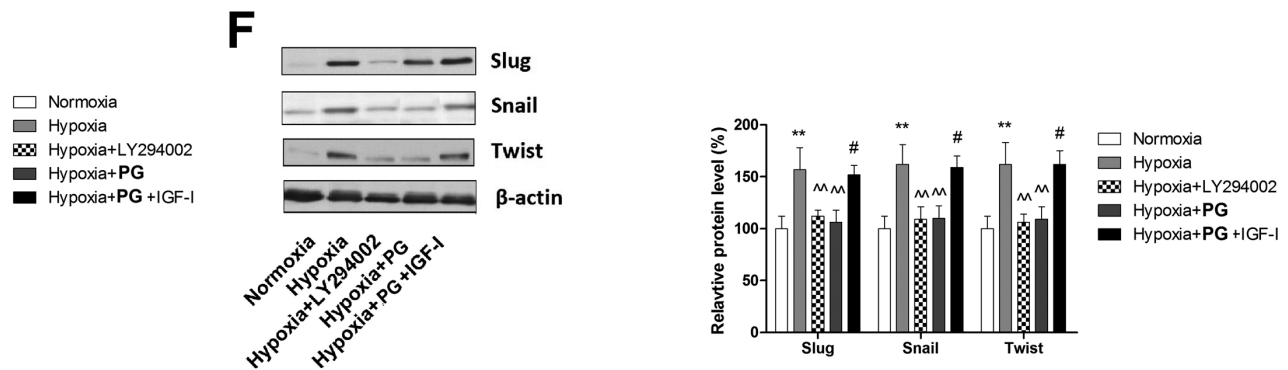

Figure 5. Modulating effect of PTEN/Akt signaling on hypoxia-induced EMT in HCT116 cells. (A) PG suppressed PTEN/Akt signaling in dose-dependent manner. (B)PG suppressed HIF-1 $\alpha$ and EMMPRIN level via PTEN/Akt signaling. (C) and (D) Akt inhibitor or mimicked the suppressing effect of PG on hypoxia-induced EMT while Akt activator abolished the suppressing effect of PG on hypoxia-induced EMT, as demonstrated by changes in EMT markers. (E) and (F) Akt inhibitor or mimicked the suppressing effect of PG on hypoxia-induced EMT while Akt activator abolished the suppressing effect of PG on hypoxia-induced EMT, as demonstrated by changes in Snail, Slug and Twist levels. The PG concentration was $50 \mu \mathrm{g} / \mathrm{ml}$ when no concentration was marked. The concentration of LY294002 and IGF-I was $20 \mu \mathrm{M}$ and $10 \mathrm{ng} / \mathrm{ml}$, respectively. LY294002 or IGF-I was added to the culture medium the same time as $\mathrm{PG}$. $\wedge \mathrm{P}<0.05$ vs. hypoxia, $\wedge \wedge \mathrm{P}<0.01$ vs. hypoxia, $\# \mathrm{P}<0.05$ vs. hypoxia $+\mathrm{PG}$. 
in vitro and in vivo [46]. In consistent with these studies, our results in this study showed that EMMPRIN was a crucial mediator involved in hypoxia-induced EMT and suppressing EMMPRIN expression could prevent hypoxia-induced EMT, further supporting the key role of EMMPRIN in colorectal cancer progression and highlighting that EMMPRIN might serve as a idea target for colorectal cancer therapy.

HIF-1 is the critical regulator in regulating the cellular response to hypoxia, and it has recently been demonstrated to be involved in tumorigensis $[47,48]$. It is well established that hypoxia contribute to cancer progression though adaptive mechanisms involving recruitment/stabilization of HIF-1a [49]. HIF- $1 \alpha$ in turn, dimerizes with HIF- $1 \beta$, translocates into the nuclei and binds to a specific sequence defined hypoxia-responsive element present in the promoter on several hypoxia-dependent target genes, which then activates a complex genetic programme designed to sustain several changes necessary to efficiently counteract the decrease in oxygen tension [49]. In addition to the induction by intratumoral hypoxia, the expression of HIF-1 1 is induced by the loss of tumor suppressors such as VHL and PTEN, activation of oncogenes, as well as by the increased activity of PI3K and/or MAPK signaling pathways $[50,51]$. In nude mouse xenograft assays, loss of HIF-1 $\alpha$ activity results in decreased tumor growth, vascularization, and energy metabolism, whereas overexpression of HIF- $1 a$ results in decreased tumor latency, increased vascular density, volume, permeability and promotes tumor growth [52]. Moreover, expression of HIF-1 $\alpha$ was unregulated in many solid tumors and has been proposed to elevate the expression of genes involved in cell invasiveness and angiogenesis, leading to an overall observation that HIF-1 1 expression correlated with highly metastatic behavior and eventually a poor prognosis[49]. Recently, hypoxia environment has been identified as a triggering factor leading to EMMPRIN overexpression, highlighting the possibility that EMMPRIN might be regulated by HIF$1 \alpha$, one of the most important responsive factors to hypoxic stimuli [53]. A later study by Ke et al provided evidence for the direct regulatory effect of HIF-1a on EMMPRIN in hypoxia conditions by demonstrating that HIF-1 $\alpha$ directly binds to a specific hypoxia-responsive element (HRE) located at -133 to -130 in the EMMPRIN promoter region and upregualtes EMMPRIN [24]. On the other hand, transcriptional regulation of EMMPRIN by Slug, which is a known downstream gene of HIF- $1 \alpha$, has also been reported [22]. It seems that HIF-1a can regulate the expression of EMMPRIN both directly and indirectly. Herein, our results showed that PG regulated the expression of EMMPRIN through modulating the level of HIF$1 \alpha$, by artificially manipulating the expression level of HIF- $1 \alpha$ in HCT116 cells, backing up the previous findings about the regulatory role of HIF-1a in EMMPRIN expression.

The role of tumor suppressor gene PTEN in regulating HIF-1 $a$ through PTEN-PI3K axis has recently been emphasized in cancer models [54]. Therefore, we examined whether PG might regulate HIF-1a level via inhibiting PTEN/Akt signaling pathway in HCT116 cells. In fact, our results did

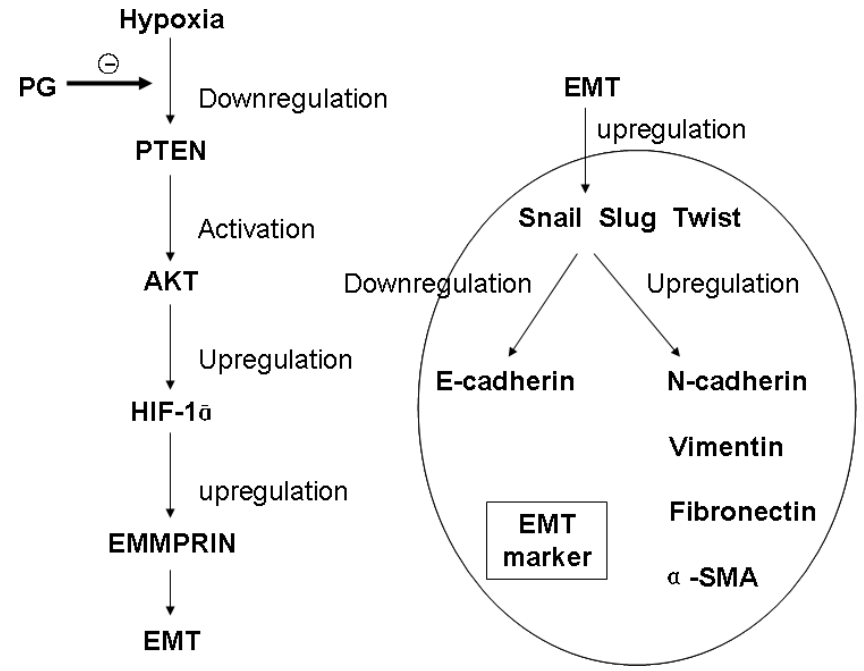

Figure 6. Overview of pathways for the suppressing effect of PG on hypoxiainduced EMTin human colorectal cancer cells HCT116.

show that PG did exert negative effect on PTEN/Akt signaling. Furthermore, both Akt signaling activator and inhibitor were utilized to confirm the regulatory PTEN/Akt signaling on the inhibitory effect of PG on HIF- $1 \alpha$ and EMMPRIN levels. Taken together, our results showed that PG suppressed hypoxia-induced EMT in colorectal cancer HCT116 cells, at least partly, by downregulating EMMPRIN via PTEN/Akt/ HIF-1a signaling pathway (Figure 6).

In conclusion, the results from this study identified a major role of EMMPRIN downregulation by PG in the prevention of the hypoxia-induced EMT of colorectal cancer cells through inhibiting PTEN/Akt/HIF-1 $\alpha$ signaling. This finding provides with a novel insight into the mechanism of PG-mediated inhibition of EMT and cancer metastasis.

Supplementary information is available in the online version of the paper.

\section{References}

[1] BABA Y, NOSHO K, SHIMA K, IRAHARA N, CHAN AT et al. HIF1A overexpression is associated with poor prognosis in a cohort of 731 colorectal cancers. The American journal of pathology. 2010; 176: 2292-301. http://dx.doi.org/10.2353/ ajpath.2010.090972

[2] LUNT SJ, CHAUDARY N, HILL RP. The tumor microenvironment and metastatic disease. Clinical \& experimental metastasis. 2009; 26: 19-34. http://dx.doi.org/10.1007/s10585-008-9182-2

[3] DACHS GU, CHAPLIN DJ. Microenvironmental control of gene expression: implications for tumor angiogenesis, progression, and metastasis. Seminars in radiation oncology. 1998; 8: 208-16. http://dx.doi.org/10.1016/S1053-4296(98)80046-5

[4] NAGARAJU GP, BRAMHACHARI PV, RAGHU G, El-RAYES BF. Hypoxia inducible factor-1alpha: Its role in colorectal carcinogenesis and metastasis. Cancer Lett. 2015. 
[5] GARBER K. Epithelial-to-mesenchymal transition is important to metastasis, but questions remain. J Natl Cancer Inst. 2008; 100: 232-3, 9.

[6] TTIERY JP, ACLOQUE H, HUANG RY, NIETO MA. Epithelialmesenchymal transitions in development and disease. Cell. 2009; 139: 871-90. http://dx.doi.org/10.1016/j.cell.2009.11.007

[7] HILL RP, MARIE-EGYPTIENNE DT, HEDLEY DW. Cancer stem cells, hypoxia and metastasis. Semin Radiat Oncol. 2009: 106-11.

[8] YANG MH, WU MZ, CHIOU SH, CHEN PM, CHANG SY et al. Direct regulation of TWIST by HIF-1alpha promotes metastasis. Nat Cell Biol. 2008; 10: 295-305. http://dx.doi. org/10.1038/ncb1691

[9] JIANG L, ZHANG S, XUAN L. Oxanthrone C-glycosides and epoxynaphthoquinol from the roots of Rumex japonicus. Phytochemistry. 2007; 68: 2444-9. http://dx.doi.org/10.1016/j. phytochem.2007.05.032

[10] ZHOU X, XUAN L, ZHANG S. [Study on the chemical constituents from Rumex japonicus Houtt]. Zhong Yao Cai. 2005; 28: 104-5.

[11] Belkin M, FITZGERALD DB. Tumor-damaging capacity of plant materials. I. Plants used as cathartics. J Natl Cancer Inst. 1952; 13: 139-55.

[12] XIE QC, YANG YP. Anti-proliferative of physcion 8-O-betaglucopyranoside isolated from Rumex japonicus Houtt. on A549 cell lines via inducing apoptosis and cell cycle arrest. BMC Complement Altern Med. 2014; 14: 377. http://dx.doi. org/10.1186/1472-6882-14-377

[13] LIAO W, LIU W, YUAN Q, LIU X, OU Y et al. Silencing of DLGAP5 by siRNA Significantly Inhibits the Proliferation and Invasion of Hepatocellular Carcinoma Cells. PloS one. 2013; 8: e80789. http://dx.doi.org/10.1371/journal.pone.0080789

[14] SATO M, NAKAI Y, NAKATA W, YOSHIDA T, HATANO K et al. EMMPRIN promotes angiogenesis, proliferation, invasion and resistance to sunitinib in renal cell carcinoma, and its level predicts patient outcome. PloS one. 2013; 8: e74313. http://dx.doi.org/10.1371/journal.pone.0074313

[15] XIE J, GAO H, JIANJUN P, YANTAO H, XUEHONG C et al. Hispidulin prevents hypoxia-induced epithelial-mesenchymal transition in human colon carcinoma cells. Am J Cancer Res. 2015; 5: 15.

[16] ZHANG J, CAO J, WENG Q, WU R, YAN Y et al. Suppression of hypoxia-inducible factor 1alpha (HIF-1alpha) by tirapazamine is dependent on eIF2alpha phosphorylation rather than the mTORC1/4E-BP1 pathway. PLoS One. 2010; 5: e13910. http://dx.doi.org/10.1371/journal.pone.0013910

[17] WANG B, XU YF, HE BS, PAN YQ, ZHANG LR et al. RNAimediated silencing of CD147 inhibits tumor cell proliferation, invasion and increases chemosensitivity to cisplatin in SGC7901 cells in vitro. Journal of experimental \& clinical cancer research: CR. 2010; 29: 61. http://dx.doi.org/10.1186/1756-9966-29-61

[18] GAO H, XIE J, PENG J, HAN Y, JIANG Q et al. Hispidulin inhibits proliferation and enhances chemosensitivity of gallbladder cancer cells by targeting HIF-1alpha. Exp Cell Res. 2015; 332: 236-46. http://dx.doi.org/10.1016/j.yexcr.2014.11.021

[19] HOU Q, TANG X, LIU H, TANG J, YANG Y et al. Berberine induces cell death in human hepatoma cells in vitro by down- regulating CD147. Cancer science. 2011; 102: 1287-92. http:// dx.doi.org/10.1111/j.1349-7006.2011.01933.x

[20] BRABLETZ T, HLUBEK F, SPADERNA S, SCHMALHOFER O, HIENDLMEYER E et al. Invasion and metastasis in colorectal cancer: epithelial-mesenchymal transition, mesenchymal-epithelial transition, stem cells and beta-catenin. Cells Tissues Organs. 2005; 179: 56-65. http://dx.doi.org/10.1159/000084509

[21] BHAT FA, SHARMILA G, BALAKRISHNAN S, ARUNKUMAR R, ELUMALAI P et al. Quercetin reverses EGF-induced epithelial to mesenchymal transition and invasiveness in prostate cancer (PC-3) cell line via EGFR/PI3K/Akt pathway. The Journal of nutritional biochemistry. 2014 Aug 1.

[22] WU J, RU NY, ZHANG Y, LIY, WEI D et al. HAb18G/CD147 promotes epithelial-mesenchymal transition through TGFbeta signaling and is transcriptionally regulated by Slug. Oncogene. 2011; 30: 4410-27. http://dx.doi.org/10.1038/ onc.2011.149

[23] FENG L, TAO L, DAWEI H, XULIANG L, XIAODONG L. HIF-1alpha expression correlates with cellular apoptosis, angiogenesis and clinical prognosis in rectal carcinoma. Pathol Oncol Res. 2014; 20: 603-10. http://dx.doi.org/10.1007/ s12253-013-9738-6

[24] KE X, FEI F, CHEN Y, XU L, ZHANG Z et al. Hypoxia upregulates CD147 through a combined effect of HIF-1alpha and Sp1 to promote glycolysis and tumor progression in epithelial solid tumors. Carcinogenesis. 2012; 33: 1598-607. http://dx.doi.org/10.1093/carcin/bgs196

[25] HU B, ZHANG H, MENG X, WANG F, WANG P. Aloeemodin from rhubarb (Rheum rhabarbarum) inhibits lipopolysaccharide-induced inflammatory responses in RAW264.7 macrophages. J Ethnopharmacol. 2014; 153: 846-53. http://dx.doi.org/10.1016/j.jep.2014.03.059

[26] MUCAJ V, SHAY JE, SIMON MC. Effects of hypoxia and HIFs on cancer metabolism. International journal of hematology. 2012; 95: 464-70. http://dx.doi.org/10.1007/s12185-012$\underline{1070-5}$

[27] MAJMUNDAR AJ, WONG WJ, SIMON MC. Hypoxiainducible factors and the response to hypoxic stress. Molecular cell. 2010; 40: 294-309. http://dx.doi.org/10.1016/j. molcel.2010.09.022

[28] CENTER MM, JEMAL A, SMITH RA, WARD E. Worldwide variations in colorectal cancer. CA Cancer J Clin. 2009; 59: 366-78. http://dx.doi.org/10.3322/caac.20038

[29] TIAN X, WANG W, ZHANG Q, ZHAO L, WEI J et al. Hypoxia-inducible factor-1alpha enhances the malignant phenotype of multicellular spheroid HeLa cells in vitro. Oncol Lett. 2010; 1: 893-7.

[30] FORSYTHE JA, JIANG BH, IYER NV, AGANI F, LEUNG SW et al. Activation of vascular endothelial growth factor gene transcription by hypoxia-inducible factor 1 . Molecular and cellular biology. 1996; 16: 4604-13. http://dx.doi.org/10.1128/ MCB.16.9.4604

[31] GUO H, MAJMUDAR G, JENSEN TC, BISWAS C, TOOLE $\mathrm{BP}$ et al. Characterization of the gene for human EMMPRIN, a tumor cell surface inducer of matrix metalloproteinases. Gene. 1998; 220: 99-108. http://dx.doi.org/10.1016/S0378$\underline{1119(98) 00400-4}$ 
[32] ELLIS SM, NABESHIMA K, BISWAS C. Monoclonal antibody preparation and purification of a tumor cell collagenasestimulatory factor. Cancer research. 1989; 49: 3385-91.

[33] JIN JS, YAO CW, LOH SH, CHENG MF, HSIEH DS et al. Increasing expression of extracellular matrix metalloprotease inducer in ovary tumors: tissue microarray analysis of immunostaining score with clinicopathological parameters. International journal of gynecological pathology : official journal of the International Society of Gynecological Pathologists. 2006; 25: 140-6. http:// dx.doi.org/10.1097/01.pgp.0000189244.57145.84

[34] SAMESHIMA T, NABESHIMA K, TOOLE BP, YOKOGAMI $\mathrm{K}$, OKADA Y et al. Expression of emmprin (CD147), a cell surface inducer of matrix metalloproteinases, in normal human brain and gliomas. International journal of cancer Journal international du cancer. 2000; 88: 21-7. http:// dx.doi.org/10.1002/1097-0215(20001001)88:1<21::AIDIJC4>3.0.CO;2-S

[35] ZHENG HC, TAKAHASHI H, MURAI Y, CUI ZG, NOMOTO K et al. Upregulated EMMPRIN/CD147 might contribute to growth and angiogenesis of gastric carcinoma: a good marker for local invasion and prognosis. British journal of cancer. 2006; 95: 1371-8. http://dx.doi. org/10.1038/sj.bjc. 6603425

[36] BORDADOR LC, LI X, TOOLE B, CHEN B, REGEZI J et al. Expression of emmprin by oral squamous cell carcinoma. International journal of cancer Journal international du cancer. 2000; 85: 347-52. http://dx.doi.org/10.1002/(SICI)1097-0215(20000201)85:3<347::AID-IJC9>3.0.CO;2-\#

[37] SIER CF, ZUIDWIJK K, ZIJLMANS HJ, HANEMAAIJER R, MULDER-STAPEL AA et al. EMMPRIN-induced MMP-2 activation cascade in human cervical squamous cell carcinoma. International journal of cancer Journal international du cancer. 2006; 118: 2991-8. http://dx.doi.org/10.1002/ijc.21778

[38] ROSENTHAL EL, ZHANG W, TALBERT M, RSISCH KP, PETERS GE. Extracellular matrix metalloprotease inducerexpressing head and neck squamous cell carcinoma cells promote fibroblast-mediated type I collagen degradation in vitro. Molecular cancer research : MCR. 2005; 3: 195-202.

[39] TANG Y, KESAVAN P, NAKADA MT, YAN L. Tumor-stroma interaction: positive feedback regulation of extracellular matrix metalloproteinase inducer (EMMPRIN) expression and matrix metalloproteinase-dependent generation of soluble EMMPRIN. Molecular cancer research : MCR. 2004; 2: 73-80.

[40] TANG Y, NAKADA MT, KESAVAN P, MCCABE F, MILLAR $\mathrm{H}$ et al. Extracellular matrix metalloproteinase inducer stimulates tumor angiogenesis by elevating vascular endothelial cell growth factor and matrix metalloproteinases. Cancer research. 2005; 65: 3193-9.

[41] MARIEB EA, ZOLTAN-JONES A, LI R, MISRA S, GHATAK $S$ et al. Emmprin promotes anchorage-independent growth in human mammary carcinoma cells by stimulating hyaluronan production. Cancer research. 2004; 64: 1229-32. http://dx.doi. org/10.1158/0008-5472.CAN-03-2832

[42] YANG JM, O'NEILL P, JIN W, FOTY R, MEDINA DJ et al. Extracellular matrix metalloproteinase inducer (CD147) confers resistance of breast cancer cells to Anoikis through inhibition of Bim. The Journal of biological chemistry. 2006; 281: 9719-27. http://dx.doi.org/10.1074/jbc.M508421200

[43] VIGNESWARAN N, BECKERS S, WAIGEL S, MENSAH J, WU J et al. Increased EMMPRIN (CD 147) expression during oral carcinogenesis. Experimental and molecular pathology. 2006; 80: 147-59. http://dx.doi.org/10.1016/j. yexmp.2005.09.011

[44] ZHU S, CHU D, ZHANG Y, WANG X, GONG L et al. EMMPRIN/CD147 expression is associated with disease-free survival of patients with colorectal cancer. Med Oncol. 2013; 30: 369. http://dx.doi.org/10.1007/s12032-012-0369-7

[45] STENZINGER A, WITTSCHIEBER D, VON WINTERFELD M, GOEPPERT B, KAMPHUES C et al. High extracellular matrix metalloproteinase inducer/CD147 expression is strongly and independently associated with poor prognosis in colorectal cancer. Hum Pathol. 2012; 43: 1471-81. http:// dx.doi.org/10.1016/j.humpath.2011.10.023

[46] LI R, PAN Y, HE B, XU Y, GAO T et al. Downregulation of CD147 expression by RNA interference inhibits HT29 cell proliferation, invasion and tumorigenicity in vitro and in vivo. Int J Oncol. 2013; 43: 1885-94.

[47] BRAHIMI-HORN MC, CHICHE J, POUYSSEGUR J. Hypoxia and cancer. Journal of molecular medicine. 2007; 85: 1301-7. http://dx.doi.org/10.1007/s00109-007-0281-3

[48] MAYNARD MA, OHH M. The role of hypoxia-inducible factors in cancer. Cellular and molecular life sciences : CMLS. 2007; 64: 2170-80. http://dx.doi.org/10.1007/s00018-007$\underline{7082-2}$

[49] WU CP, DU HD, GONG HL, LI DW, TAO L et al. Hypoxia promotes stem-like properties of laryngeal cancer cell lines by increasing the CD133+ stem cell fraction. Int J Oncol. 2014; 44: $1652-60$.

[50] SEMENZA GL. Hypoxia-inducible factor 1: oxygen homeostasis and disease pathophysiology. Trends in molecular medicine. 2001; 7: 345-50. http://dx.doi.org/10.1016/S14714914(01)02090-1

[51] GAO H, XIE J, PENG J, HAN Y, JIANG Q et al. Hispidulin inhibits proliferation and enhances chemosensitivity of gallbladder cancer cells by targeting HIF-1alpha. Experimental cell research. 2014.

[52] HOPFL G, OGUNSHOLA O, GASSMANN M. HIFs and tumors--causes and consequences. American journal of physiology Regulatory, integrative and comparative physiology. 2004; 286: R608-23. http://dx.doi.org/10.1152/ajpregu.00538.2003

[53] KUNG AL, WANG S, KLCO JM, KAELIN WG, LIVINGSTON DM. Suppression of tumor growth through disruption of hypoxia-inducible transcription. Nature medicine. 2000; 6 : 1335-40. http://dx.doi.org/10.1038/82146

[54] YANG H, ZOU W, CHEN B. Overexpression of CD147 in ovarian cancer is initiated by the hypoxic microenvironment. Cell biology international. 2013; 37: 1139-42. http://dx.doi. org/10.1002/cbin.10131

[55] MA J, HAN LZ, LIANG H, MI C, SHI H et al. Celastrol inhibits the HIF-1alpha pathway by inhibition of mTOR/p70S6K/ eIF4E and ERK1/2 phosphorylation in human hepatoma cells. Oncol Rep. 2014; 32: 235-42. 
A
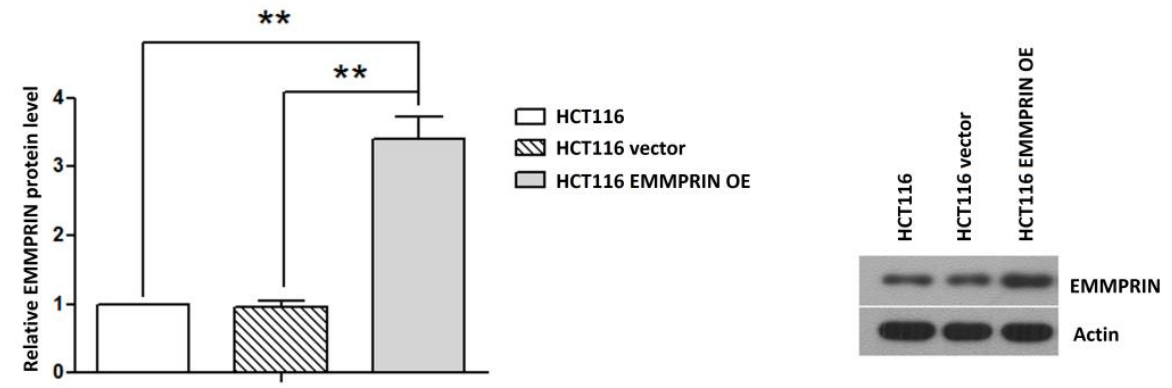

B

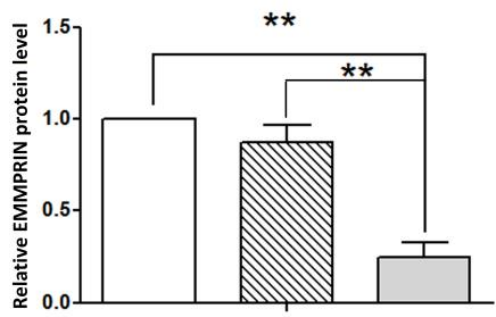

$\square$ HCT116

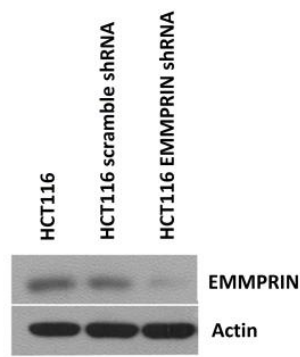

Supplementary Figure 1. A: Overexpression of EMMPRIN in HCT116 cells. B:

Knockdown of EMMPRIN in HCT116 cells. Blots were representative of three independent experiments. ${ }^{* *} \mathrm{P}<0.01$ 